\title{
Penerapan Metode Analytical Hierarchy Process Untuk Keputusan Dosen Berprestasi Pada Fakultas Teknik Universitas Al Washliyah Labuhanbatu
}

\author{
Shabrina Rasyid Munthe \\ Teknik informatika, Fakultas Teknik, Universitas Al Washliyah Labuhanbatu, Rantauprapat, Indonesia \\ Email: shabrinarasyidmunthe@gmail.com ${ }^{1 *}$
}

\section{Info Artikel \\ Article history: \\ Received 052019 \\ Revised 062019 \\ Accepted 082019 \\ Kata Kunci: \\ Metode AHP \\ Kinerja \\ Sistem Keputusan \\ Dosen Berprestasi \\ Penilaian Kinerja}

\section{Penulis Korespondensi*:}

Shabrina Rasyid Munthe shabrinarasyidmunthe@gmail.com Rantauprapat

\begin{abstract}
In establishing the criteria for this evaluation, we want to make it easier for the lecturers' performance assessors to input their ratings. Additionally, with the establishment of standards designed to facilitate the assignment of outstanding lecturers. The AHP algorithm (Analitycal Hierarchy Process) can be used to resolve issues pertaining to the performance evaluation of outstanding lecturers at the University of Alwasliyah Labuhanbatu's Faculty of Engineering. The AHP algorithm (Analitycal Hierarchy Process) can be used to evaluate the output of outstanding lecturers via a database application. It is anticipated that by using this evaluation decision support framework, the faculty of engineering will be able to resolve decisionmaking issues during the assessment. Then it can be used to streamline the process of rewarding or compensating outstanding lecturers within the faculty of engineering.
\end{abstract}

\begin{abstract}
Abstrak
Dalam menetapkan kriteria evaluasi ini, kami ingin mempermudah penilai kinerja dosen untuk menginput peringkatnya. Selain itu, dengan ditetapkannya standar yang dirancang untuk mempermudah penugasan dosen berprestasi. Algoritma AHP (Analitycal Hierarchy Process) dapat digunakan untuk menyelesaikan masalah yang berkaitan dengan evaluasi kinerja dosen berprestasi di Fakultas Teknik Universitas Alwasliyah Labuhanbatu. Algoritma AHP (Analitycal Hierarchy Process) dapat digunakan untuk mengevaluasi output dosen berprestasi melalui aplikasi database. Diantisipasi dengan menggunakan kerangka kerja dukungan keputusan evaluasi ini, fakultas teknik akan dapat menyelesaikan masalah pengambilan keputusan selama penilaian. Kemudian dapat digunakan untuk merampingkan proses menghadiahi atau mengkompensasi dosen berprestasi di lingkungan fakultas teknik.
\end{abstract}

\section{PENDAHULUAN}

Tingkat pertumbuhan ekonomi yang semakin meningkat tiap tahunnya, mendorong terjadinya persaingan bisnis pada perusahaan dan organisasi baik bergerak dalam bidang pendidikan di indonesia. Dalam lingkungan bisnis yang sangat komfetitif tersebut, perusahaan dan organisasi baik bergerak dalam bidang pendidikan tersebut dituntut untuk menempuh langkah-langkah strategis agar dapat bersaing dalam kondisi apapun serta memiliki keunggulan yang dapat membedakan antara perusahaan dan organisasi baik bergerak dalam bidang pendidikan satu dengan yang lainnya. Sehingga dapat memberikan pelayanan yang terbaik kepada pelanggan dan perusahaan. Oleh karena itu, diperlukan suatu sistem pengukuran kinerja untuk mengevaluasi kinerja perusahaan agar dapat menjamin apakah perusahaan tersebut berjalan dengan benar dalam upaya pencapaiannya. Menurut Mangkunegara, kinerja merupakan hasil kerja seorang karyawan dalam hal kualitas dan kuantitas yang dicapai saat menjalankan tugasnya sesuai dengan tanggung jawab yang ditugaskan kepadanya [1]. Susetyo mendefinisikan penilaian kinerja sebagai operasi yang terus menilai keberhasilan program, terutama dalam hal kemajuan terhadap tujuan jangka panjang.[2]. Menurut Muskamal, pengukuran kerja dilakukan untuk memastikan tingkat efektivitas dan produktivitas organisasi berdasarkan volume pekerjaan yang diperlukan untuk diselesaikan dalam waktu satu tahun [3].

Berkenaan dengan pengukuran kinerja, sangat penting untuk memilih langkah-langkah kinerja yang tepat yang terkait langsung dengan tujuan strategis perusahaan, karena banyak kampus melakukan pengukuran yang 
tidak relevan yang tidak terkait langsung dengan tujuan strategis universitas. Dengan saran perubahan tersebut, Fakultas Teknik di Universitas Alwasliyah Labuhanbatu akan memastikan dalam mengambil tindakan pencegahan yang tepat untuk mencegahnya terulang kembali.

\section{METODE PENELITIAN}

Sebagai sistem informasi berbasis komputer yang adaptif, interaktif, dan mudah dipahami. Dirancang khusus untuk membantu penyelesaian masalah manajemen yang tidak terstruktur dan untuk meningkatkan efisiensi pengambilan keputusan.

\section{a. Komponen Sistem Pendukung Keputusan}

Elemen-elemen yang terlibat didalam proses pengambilan keputusan ada empat, yaitu[4]:

1. Data Manajemen

Menyertakan database yang menyimpan informasi yang berkaitan dengan sejumlah keadaan dan diatur oleh Database Management Systems (DBMS).

2. Model Management

Model keuangan, matematika, ilmu manajemen, atau analitis diperlukan, seperti halnya perangkat lunak manajemen.

3. Communication(Dialog Subsystem)

Subsistem ini memungkinkan pengguna untuk terhubung dan memerintahkan DSS. Ini memerlukan fasilitas interface.

4. Knowledge Mangement.

Knowledge Mangement ini dapat digunakan bersama dengan subsistem lain atau sebagai komponen mandiri. Sepanjang berbagai proses manajemen, proses pengambilan keputusan telah sangat dipengaruhi oleh DSS (Decision Support Systems) yang berevolusi. Proses itu sendiri harus melalui beberapa tahap sebelum menyimpulkan dengan sebuah keputusan.

b. Tahapan Pemodelan dalam DSS (Decision Support Systems)

Tahapan-tahapan pengambilan keputusan antara lain[5]:

1. Studi kelayakan (Intelegence) : Mengamati dan mencari hal-hal yang perlu diperbaiki.

2. Perancangan (Design) : Tahap ini merupakan proses menemukan, mengembangkan dan menganalisis berbagai alternatif tindakan yang mungkin.

3. Pemilihan (Choice) : Memilih satu rangkaian tindakan tertentu dari beberapa yang tersedia.

4. Implementasi (Implementation) : Menilai pilihan-pilihan yang lalu.

c. Model Analitycal Hierarchy Process (AHP)

Proses pengambilan keputusan pada dasarnya adalah proses memilih opsi. Metode AHP disusun secara fungsional, dengan pengalaman manusia sebagai masukan utamanya. Kehadiran hirarki memungkinkan masalah rumit atau tidak terstruktur dipecah menjadi sub-masalah dan kemudian diatur dengan cara hierarki. Metode AHP menunjukkan proses pengambilan keputusan dengan berbagai cara. Salah satunya dijelaskan secara grafis untuk memastikan bahwa semua orang yang terlibat dalam proses pengambilan keputusan mengenalinya.

\section{DISKUSI DAN HASIL}

a. Prosedur AHP (Analitycal Hierarchy Process)

Pada dasarnya, prosedur atau langkah-langkah dalam metide AHP meliputi:

1. Tentukan sifat masalah dan solusi dari masalah tersebut. lalu bangun hierarki masalah. Tujuan pembentukan hierarki adalah untuk menetapkan tujuan tingkat atas yang merupakan tujuan keseluruhan sistem.

2. Menentukan prioritas elemen

a. Langkah pertama dalam memutuskan prioritas elemen adalah melakukan perbandingan sesuai pasangannya, yang membandingkan elemen berpasangan sesuai dengan kriteria yang ditentukan.

b. Matriks perbandingan berpasangan yang diisi dengan angka untuk menunjukkan nilai relatif dari satu variabel ke variabel lainnya.

3. Sintesis

Untuk menetapkan tujuan keseluruhan, pertimbangan untuk perbandingan yang dipasangkan disintesis.

Pemindahan ini melakukan tugas berikut:

a. Meringkas nilai di setiap kolom matriks.

b. Untuk mencapai normalisasi matriks, bagi setiap nilai kolom dengan panjang kolom total.

c. Menghitung nilai rata-rata dengan menambahkan nilai di setiap baris dan membaginya dengan jumlah komponen. 
4. Mengukur Konsistensi

Penting untuk memahami tingkat konsistensi dalam pengambilan keputusan karena kami tidak ingin membuat keputusan berdasarkan ketidakkonsistenan. Hal-hal yang dilakukan dalam langkah ini adalah:

a. Kalikan setiap nilai pada kolom pertama dengan prioritas relatif elemen pertama, nilai pada kolom kedua dengan prioritas relatif elemen kedua dan seterusnya.

b. Jumlahkan setiap baris

c. Hasil dari penjumlahan baris dibagi dengan elemen prioritas relatif yang bersangkutan.

d. Jumlahkan hasil bagi diatas dengan banyaknya elemen yang ada hasilnya disebut $\lambda$ maks.

5. Hitung Consistency Index (CI) dengan rumus:

$\mathrm{CI}=(\lambda \operatorname{maks}-n) / \mathrm{n}$ atau

$\mathrm{CI}=\underline{t-n}$

$n-1$.

Dimana $\mathrm{n}=$ banyaknya elemen

6. Hitung Rasio Consistency / Consistency Ratio (CR) dengan rumus:

$\mathrm{CR}=\mathrm{CI} / \mathrm{RC}$

Dimana: $\mathrm{CR}=$ Consistency Ratio

$\mathrm{CI}=$ Consistency Index

IR = Indeks Random Consistency

7. Memeriksa konsistensi hierarki. Jika nilainya lebih dari $10 \%$, maka penilaian data judgment harus diperbaiki. Namun jika rasio konsistensi (CI/IR) kurang atau sama dengan 0,1 maka hasil perhitungan bisa dinyatakan benar.

Daftar Indeks Random Konsistensi (IR) bisa dilihat dalam tabel.1.

Tabel 1 Daftar Indeks Random Konsistensi

\begin{tabular}{|c|c|}
\hline Ukuran Matriks & Nilai IR \\
\hline 1,2 & 0,00 \\
\hline 3 & 0.58 \\
\hline 4 & 0.90 \\
\hline 5 & 1.12 \\
\hline 6 & 1.24 \\
\hline 7 & 1.32 \\
\hline 8 & 1.41 \\
\hline 9 & 1.45 \\
\hline 10 & 1.49 \\
\hline 11 & 1.51 \\
\hline 12 & 1.48 \\
\hline 13 & 1.56 \\
\hline 14 & 1.57 \\
\hline 15 & 1.59 \\
\hline
\end{tabular}

\section{B. Impelementasi}

Bagian ini akan menjelaskan langkah-langkah yang terlibat dalam proses AHP untuk memproses data yang digunakan untuk mengukur hasil kinerja dosen. Proses ini dikonversi menjadi kode sumber dalam bahasa pemrograman Visual Basic dalam kerangka kerja yang dikembangkan, dan data nilai dosen diambil dari database dosen.

1. Tampilan Login

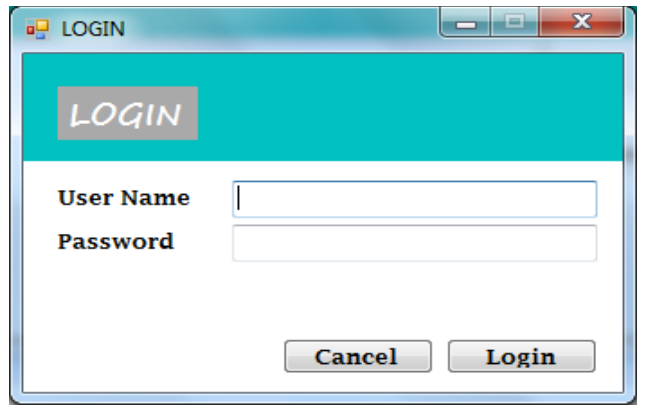

Gambar 1. Tampilan Halaman Login Admin 
2. Tampilan Hasil Nilai SPK

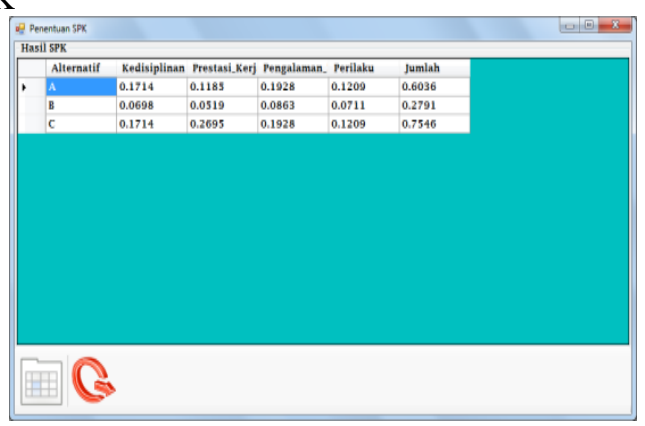

Gambar 2. Tampilan Form Hasil SPK

\section{KESIMPULAN}

Dalam menentukan kriteria penilaian ini agar dapat memudahkan para penilai kinerja dosen yang akan diinputkan nilainya. Dan dengan penentuan kriteria yang telah ditetapkan agar mudah menetapkan dosen yang berprestasi tersebut. Algoritma AHP (Analitycal Hierarchy Process) bisa digunakan untuk menyelesaikan permasalahan dalam hal penilaian kinerja dosen berprestasi di Fakultas Teknik Universitas Alwasliyah Labuhanbatu Algoritma AHP (Analitycal Hierarchy Proses) dapat diterapkan pada sebuah bentuk aplikasi database dalam penilaian kinerja dosen berprestasi tersebut. Dengan menggunakan sistem pendukung keputusan penilaian ini, diharapkan dapat menyelesaikan permasalahan dalam pengambilan keputusan dalam penilaian yang akan dilakukan oleh pihak fakultas teknik. Maka dapat memberikan kemudahan dalam memutuskan fakultas teknik dalam memberikan reward atau tunjangan kinerja kepada dosen yang berprestasi.

\section{REFERENSI}

[1] Palahudin, Ismartaya, and J. D. Wetik, "Kompetensi Sumber Daya Manusia dan Iklim Organisasi terhadap Kinerja Pegawai PDAM Tirta Pakuan Kota Bogor,” Manag. Stud. Entrep. J., vol. 2, no. 1, pp. 1-6, 2019, doi: 10.37385/MSEJ.V2I1.155.

[2] A. R. Sahaya and H. C. Wahyuni, "Pengukuran Kinerja Karyawan Dengan Metode Human Resources Scorecard Dan AHP (Studi Kasus : PT. Bella Citra Mandiri Sidoarjo),” J. Stud. Manaj. dan Bisnis, vol. 4, no. 2, pp. 137-145, Dec. 2017, doi: 10.21107/jsmb.v4i2.3962.

[3] R. Irawati and D. A. Carollina, "ANALISIS PENGARUH BEBAN KERJA TERHADAP KINERJA KARYAWAN OPERATOR PADA PT GIKEN PRECISION INDONESIA,” Inovbiz J. Inov. Bisnis, vol. 5, no. 1, p. 51, 2017, doi: 10.35314/inovbiz.v5i1.171.

[4] A. Lasarudin, "MENGGUNAKAN METODE ANALITYCHAL HIERARCHY PROCESS," FEBRUARI, vol. 1, no. 1, pp. 6-10, 2021, Accessed: Apr. 17, 2021. [Online]. Available: https://journal.umgo.ac.id/index.php/juik/index.

[5] J. Wijayanto and S. Juanita, "PEMODELAN SISTEM PENUNJANG KEPUTUSAN PEMILIHAN GURU TERBAIK SMA YP-BDN MENGGUNAKAN AHP DAN SAW,” Jan. 2021.

[6] A. Suseno and S. Sutrisno, "Penerapan Analitycal Hirarchi Process (AHP) dalam Sistem Penilaian Kinerja Karyawan Sebagai Acuan Untuk Promosi Jabatan Di PT. XYZ," J. Media Tek. dan Sist. Ind., vol. 3, no. 2, p. 73, 2020, doi: 10.35194/jmtsi.v3i2.543.

[7] M. I. H. Saputra and N. Nugraha, "SISTEM PENDUKUNG KEPUTUSAN DENGAN METODE ANALYTICAL HIERARCHY PROCESS (AHP) (STUDI KASUS: PENENTUAN INTERNET SERVICE PROVIDER DI LINGKUNGAN JARINGAN RUMAH)," J. Ilm. Teknol. dan Rekayasa, vol. 25, no. 3, pp. 199-212, 2020, doi: 10.35760/tr.2020.v25i3.3422. 